Article

\title{
Impact of Two Forms of Daily Preventive Zinc or Therapeutic Zinc Supplementation for Diarrhea on Hair Cortisol Concentrations Among Rural Laotian Children: A Randomized Controlled Trial
}

\author{
Guy-Marino Hinnouho ${ }^{1, *} \mathbb{0}$, Robin M. Bernstein ${ }^{2,3}$, Maxwell A. Barffour ${ }^{1,4}$, \\ Charles D. Arnold ${ }^{1}{ }^{1}$, K. Ryan Wessells ${ }^{1}$, Kethmany Ratsavong ${ }^{5}$, Bangone Bounheuang ${ }^{5}$, \\ Sengchanh Kounnavong ${ }^{5}$ and Sonja Y. Hess ${ }^{1}$ (D) \\ 1 Program in International and Community Nutrition, Department of Nutrition, University of California, \\ Davis, CA 95616, USA; mabarffour@ucdavis.edu (M.A.B.); cdarnold@ucdavis.edu (C.D.A.); \\ krwessells@ucdavis.edu (K.R.W.); syhess@ucdavis.edu (S.Y.H.) \\ 2 Department of Anthropology, University of Colorado, Boulder, CO 80309, USA; \\ robin.bernstein@colorado.edu \\ 3 Health and Society Program, Institute for Behavioral Science, University of Colorado, Boulder, \\ CO 80309, USA \\ 4 Public Health Program, College of Health and Human Services, Missouri State University, Springfield, \\ MO 65897, USA \\ 5 Lao Tropical and Public Health Institute, Ban Kaognot, Sisattanack District, Vientiane 01030, Laos; \\ kethmany.ratsavong@gmail.com (K.R.); bangonbounheuang@gmail.com (B.B.); \\ sengchanhkounnavong@hotmail.com (S.K.) \\ * Correspondence: gmhinnouho@ucdavis.edu; Tel.: +1-(530)-752-1992
}

Received: 30 November 2018; Accepted: 23 December 2018; Published: 27 December 2018

\begin{abstract}
Zinc supplementation has been shown to reduce the morbidity burden among young children, and may reduce chronic stress. Hair cortisol has been promoted as an indicator of chronic stress. We assessed the impact of different strategies for delivering supplementary zinc on hair cortisol concentrations (HCC) in young Laotian children and examined risk factors associated with HCC. In a randomized double-blind controlled trial (NCT02428647), children aged 6-23 mo were randomized to one of four intervention groups and followed for $\sim 36$ weeks: daily preventive zinc (PZ) tablets (7 mg/day), daily multiple micronutrient powder (MNP) sachets (containing $10 \mathrm{mg}$ zinc and 14 other micronutrients), therapeutic zinc (TZ) supplements for diarrhea treatment (20 mg/day for 10 days) or daily placebo powder. HCC of 512 children was assessed at baseline and endline. ANCOVA and linear regression models were used to assess group differences in HCC and to examine the risk factors associated with HCC, respectively. At enrollment, mean HCC was $28.8 \pm 43.9 \mathrm{pg} / \mathrm{mg}$. In models adjusted for age at enrollment, health district, and baseline HCC there was no overall effect of the interventions on endline HCC and change in HCC. When controlling for additional predetermined covariates, there was a marginally significant effect on change in HCC $(p=0.075)$ with a slightly lower reduction of HCC in TZ compared to PZ (mean change (95\% CI): $-4.6(-7.0 ;-2.3)$ vs. $-9.4(-11.7$; $-7.0) \mathrm{pg} / \mathrm{mg} ; p=0.053)$. At baseline, consumption of iron rich foods was negatively associated with HCC, whereas AGP ( $\alpha 1$-acid glycoprotein) levels, elevated AGP and C-reactive protein and high soluble transferrin receptor were positively associated with HCC. In young Laotian children, MNP, PZ and TZ had no impact on HCC. The marginal difference in change in HCC between the PZ and $\mathrm{TZ}$ groups was too small to be considered of health significance.
\end{abstract}

Keywords: zinc supplementation; micronutrient powder; MNP; hair cortisol; chronic stress; young children; Lao PDR 


\section{Introduction}

Chronic stress, as a result of economic deprivation, inadequate nutrition and/or poor health status, experienced by children in low-income countries, can have detrimental consequences on their wellbeing, physical and mental health later in life [1-3]. Although unclear, the mechanism underlying the relationship between chronic stress and adverse health outcomes is hypothesized to be an increased activation of the hypothalamic-pituitary-adrenal (HPA) axis [4], which may trigger an elevation in circulating cortisol levels [5].

Traditional biological specimens for cortisol measurement include saliva, blood or urine samples, each with its advantages and disadvantages [6]. Serum and saliva are subject to major physiological daily fluctuations and thus reflect acute stress [7], limiting their usefulness as indicators of stress levels over long periods of time [8]. In addition, blood collection for assessment of serum cortisol is invasive and stressful for children and may increase circulating cortisol levels, while collection of saliva, although less-invasive, presents other challenges related to protocol compliance [9] and collection methods [10]. In contrast to serum and saliva samples, a 24-h urine collection is non-invasive and is used for measuring cortisol secretion over a prolonged period [11]. However, a 24-h urine collection is time-consuming, laborious and presents some difficulties in regards to the analytical method and protocol compliance [8].

There is growing evidence that hair offers an alternative suitable matrix for monitoring long-term cortisol profiles by capturing systemic cortisol exposure over longer periods of time $[8,12,13]$. Hair is easy to collect, non-invasive, less stressful and unlike blood, saliva and urine which require frozen storage, can be stored at room temperature in a sealed envelope. Only a small amount of hair is required to assess information prior to hair collection [13] and analysis of sections along the hair shaft enables differentiation between several time periods in the past [6]. Furthermore, it has been reported that hair cortisol is stable over time [14], has a high overall validity and test-retest reliability [15] and is not found to be influenced by acute stress [16].

While hair cortisol concentration (HCC) has been widely used as a biomarker of chronic stress in studies among adults $[17,18]$, it is only emerging now as a promising marker of childhood chronic stress. To date there is no consensus on the best approach to assess chronic stress in young children [19]. The main focus of the existing literature on HCC as a biomarker of chronic stress in young children has been limited to exploring the main determinants of HCC in terms of chronic stress exposure, such as low socio-economic status and maternal distress [20]. Here, we investigate the utility of HCC as a stress biomarker in the context of a randomized controlled trial of zinc supplementation among 6 to 23 months old children.

Adequate zinc nutrition is essential for human health because zinc is involved in numerous metabolic processes as a catalyst, a regulatory ion or structural element of proteins [21]. Because zinc participates in so many metabolic pathways, zinc deficiency affects multiple physiological systems, children's physical growth, the risk and severity of a variety of infections and pregnancy outcomes. Preventive zinc supplementation provided daily in form of tablets or syrup has been shown to reduce the incidence of diarrhea and acute lower respiratory infection among young children [22-25] which in turn may reduce chronic stress. Zinc is also commonly included in multiple micronutrient powders (MNP), which have consistently been found to reduce the risk of anemia and increase iron status [26]. However, a recent meta-analysis of MNPs found a significant association between MNP and an increase in diarrhea incidence [27], which was assumed to be due to potentially adverse effects of iron. Lastly, therapeutic zinc supplementation, as recommended by the World Health Organization (WHO) and UNICEF [28], shortens the duration of diarrhea and reduces the number of children whose diarrhea persists for 7 days [29].

Hair zinc, a biological marker of long-term zinc nutrition, has been reported to be negatively associated with HCC among 4-6 years old children in Vancouver [30], and the authors speculated that the inverse relationship between zinc and cortisol concentrations in hair may suggest some chronic stress in the study population. Whether the above-mentioned various regimens of zinc 
supplementation with or without other micronutrients have an impact on HCC is unknown. Therefore, in the present study, we aimed to: (1) assess the impact of different strategies for delivering supplementary zinc on HCC in young Laotian children, (2) examine the risk factors associated with baseline HCC and, (3) assess the association between endline HCC and the diarrhea and fever burden in the previous 3 months.

\section{Materials and Methods}

\subsection{Ethical Approval}

Ethical approval of the trial was provided by the National Ethics Committee for Health Research (Lao PDR) and the Institutional Review Board of the University of California, Davis (UC Davis). The trial was registered at www.clinicaltrials.gov (NCT02428647).

\subsection{Study Design}

We implemented a randomized controlled double-blind community-based trial, known as the Lao Zinc Study, from September 2015 until April 2017 in rural communities in Khammouane Province, central Lao PDR with the aim to compare two forms of daily preventive zinc supplementation (tablets and MNP) versus therapeutic zinc supplementation for diarrhea on young children's physical growth and other health outcomes. A detailed protocol of the Lao Zinc Study has been published elsewhere [31]. Briefly, written informed consent (documented by either a signature or a fingerprint in the presence of a neutral witness) was obtained from one of the child's primary caregivers (mother, father or legal guardian). Children were considered eligible if they were 6-23 months of age, and their families accepted weekly visits, planned residency within the study area for the duration of the study and signed informed consent. Children were ineligible if they met one of the following criteria: severe anemia $(\mathrm{Hb}<70 \mathrm{~g} / \mathrm{L})$, weight-for-length $z$-score $(\mathrm{WLZ})<-3$ [32], presence of bipedal edema, severe illness warranting hospital referral, congenital abnormalities potentially interfering with growth, chronic medical condition (e.g., malignancy) requiring frequent medical attention, known human immunodeficiency virus (HIV) infection of index child or child's mother, currently consuming zinc supplements or current participation in another clinical trial.

\subsection{Sample Size Estimation}

A sample size of 133 children per study intervention group was estimated to be able to detect a difference in mean HCC between any two intervention groups with an effect size of 0.4 , a power of $80 \%$ and a type I error of $5 \%$. Considering the absence of information of the impact of micronutrient interventions on HCC, the effect size of 0.4 was informed by other indicators of micronutrient status such as plasma zinc and ferritin [22,33]. An attrition rate of 30\% was considered to account for drop out and possible failure to successfully collect hair at both time points (total sample size $=760$ ). Sample size estimation was done with the use of SAS software (version 9.4; SAS Institute, Inc., Cary, NC, USA).

\subsection{Randomization and Intervention Products}

Eligible children were individually randomized to one of the four following intervention groups: (1) the preventive zinc (PZ) group, receiving $7 \mathrm{mg}$ of a daily preventive dispersible zinc supplement plus a placebo therapeutic tablet for diarrhea; (2) the MNP group receiving a daily preventive MNP containing $10 \mathrm{mg}$ zinc as zinc gluconate and $6 \mathrm{mg}$ iron as ferrous fumarate along with 13 other micronutrients plus a placebo therapeutic tablet for diarrhea; (3) the therapeutic zinc (TZ) group, receiving a daily preventive placebo tablet plus $20 \mathrm{mg}$ of therapeutic zinc for diarrhea for 10 days; or (4) the control group, receiving a daily placebo preventive powder plus a therapeutic placebo tablet for diarrhea. This new MNP formulation containing a lower amount of iron and a higher amount of zinc dose than current formulations was tested to address the concerns of potential adverse effects of MNP on diarrhea. In addition to zinc and iron, it contained $0.56 \mathrm{mg}$ copper as copper sulphate anhydrous, 
$17 \mu \mathrm{g}$ selenium as selenium selenite, $90 \mu \mathrm{g}$ iodine as potassium iodate, $400 \mu \mathrm{g}$ RE vitamin A, $5 \mu \mathrm{g}$ vitamin $\mathrm{D}$ (cholecalciferol), $5 \mathrm{mg}$ vitamin $\mathrm{E}$ (dl- $\alpha$-tocopherol acetate), $30 \mathrm{mg}$ ascorbic acid, $0.5 \mathrm{mg}$ thiamin, $0.5 \mathrm{mg}$ riboflavin, $6 \mathrm{mg}$ niacin, $0.5 \mathrm{mg}$ vitamin B-6, $0.9 \mu \mathrm{g}$ vitamin B-12, and $150 \mu \mathrm{g}$ folic acid. All children received oral rehydration salts (ORS) to be taken during diarrhea episodes.

The preventive zinc, therapeutic zinc and placebo tablets were produced by Nutriset SAS (Malaunay, France). The powder supplements (MNP and placebo) were produced by DSM Fortitech Asia Pacific Sdn Bhd (Banting, Malaysia). Caregivers were instructed to dissolve the tablet supplements (one dose per day for PZ; one tablet daily for 10 days as part of diarrhea management for TZ) with clean water or breast milk and spoon feed the child $30 \mathrm{~min}$ before or after a meal. For the powder supplements, they were advised to mix the entire content of the sachet with a semi-solid or mashed food.

\subsection{Data Collection}

Children's anthropometry (weight, length and mid-upper arm circumference (MUAC)) were measured at baseline and endline and maternal weight and height were measured once. All anthropometric measurements were completed in duplicate [34]. Information on maternal and household demographic and socio-economic status (education, occupation, ethnicity, household size and composition, housing material, household assets, and land ownership), food security and hygiene and sanitation practices were collected at baseline. Information on infant and young child feeding (IYCF) practices (breastfeeding, formula feeding, 24-h and 7-day food frequency questionnaire) were collected at baseline and every four weeks.

At baseline and endline, venous blood samples were collected to assess biomarkers of nutritional (ferritin, soluble transferrin receptor (sTfR), retinol binding protein (RBP)) and inflammatory (C-reactive protein (CRP) and $\alpha 1$-acid glycoprotein (AGP)) status by combined sandwich enzyme-linked immunosorbent assay (ELISA) technique at VitMin Lab (Willstaett, Germany) [35].

\subsection{Morbidity Surveillance and Supplement Administration}

Children enrolled in the trial remained under observation and received their assigned supplements daily for a period of $\sim 36$ weeks. Each household was visited weekly by a morbidity surveillance worker who recorded reported morbidity symptoms for each day of the previous week and delivered the respective preventive supplements. Recorded morbidity symptoms included fever, diarrhea (number and consistency of stools), respiratory symptoms (cough and nasal discharge) and any other symptoms of concern. Axillary temperature was measured once every four weeks and whenever fever was reported within $24 \mathrm{~h}$ of the home visit.

\subsection{Hair Samples Collection and Hair Cortisol Analyses}

Due to the large study area causing logistical challenges, participants were selected for separate subgroup analyses based on logistical feasibility [31]. In an effort to obtain information on micronutrient and inflammatory status and HCC, venous and hair samples were collected in the same subgroup of children from a convenience sample. A total of 788 children provided hair samples at baseline and 694 children at endline, of which 529 children who had both baseline and endline samples were selected for analyses of HCC. The endline hair samples were collected $~ 32-36$ weeks after the baseline hair collection. Approximately 10-20 mg of hair was cut as close to the scalp as possible from the center of the nape of the neck $(\sim 2 \mathrm{~cm}$ above hair line), or a nearby location, in case of insufficient hair. All hair samples were placed in small paper envelopes and subsequently stored in individual Ziploc bags, at room temperature.

Hair cortisol analysis was successfully performed in 512 children who provided adequate hair quantity at both baseline and endline assessments. Approximately $10 \mathrm{mg}$ of hair was weighed (mean hair weight $\pm \mathrm{SD}$ was $10.06 \pm 0.75 \mathrm{mg}$ ) and placed into $2 \mathrm{~mL}$ polypropylene tubes. Hair was washed with isopropanol, dried under a stream of air in a fume hood for $48 \mathrm{~h}$, and then ground with one 
stainless steel ball per tube for $10 \mathrm{~min}$ at $25 \mathrm{mHz}$, using a Retsch $400 \mathrm{MM}$ ball mill (Verder Scientific, Newton, PA, USA). Ground samples were incubated with $1 \mathrm{~mL}$ of HPLC-grade methanol on a rotating platform overnight at $170 \times g$. The next day, samples were centrifuged for $12 \mathrm{~min}$ at $4200 \times g$, and $875 \mu \mathrm{L}$ of supernatant was removed and transferred to a new $2 \mathrm{~mL}$ tube. The supernatant was dried down under a constant stream of nitrogen gas for $\sim 15$ min using a Micro-Vap system (Organomation, Berlin, MA, USA). Samples were then reconstituted with $0.5 \mathrm{~mL}$ EIA buffer solution, and reconstituted samples were assayed using a commercially available salivary cortisol kit (Salimetrics, State College, PA, USA) previously validated for use with human hair samples [30].

\subsection{Definitions}

Stunting, underweight and wasting were defined as length-for-age $z$-scores (LAZ) $<-2$, weight-for-age $z$-scores (WAZ) $<-2$ and weight-for-length $z$-scores (WLZ) $<-2$ respectively [32]. Low MUAC was defined as MUAC $\leq 12.5 \mathrm{~cm}$. Elevated CRP and AGP were defined as CRP $>5 \mathrm{mg} / \mathrm{L}$ and AGP $>1 \mathrm{~g} / \mathrm{L}$, respectively. Low ferritin was defined as plasma ferritin $(\mathrm{pF})<12 \mu \mathrm{g} / \mathrm{L}$ and high sTfR as $\mathrm{sTfR}>8.3 \mathrm{mg} / \mathrm{L}$. A child was considered breastfed if breastfeeding was reported at least once in the past month.

\subsection{Statistical Analyses}

A statistical analyses plan describing the statistical procedures was published prior to the analyses [36]. Analyses were done based on complete-case intention-to-treat, and the intervention group was considered the primary exposure variable. All analyses were undertaken using Stata 14 (StataCorp 2015, College Station, TX, USA).

To assess the first objective, we examined the difference in mean HCC at endline and the magnitude of change in HCC between baseline and endline among the four intervention groups. Baseline and endline HCC were log-transformed to normality but the difference in baseline and endline was normally distributed and thus not transformed. ANCOVA regression models were used to assess treatment effect on HCC in minimally adjusted models (including baseline value of HCC, age at baseline and health district) and fully-adjusted models (including variables in the minimally adjusted models and pre-specified variables determined to be associated with outcome $(p<0.1)$ ). Potential effect modifiers by baseline variables were explored by incorporating interaction terms in the statistical models. Interaction terms were further examined if marginally significant $(p<0.1)$.

For the second objective, we examined potential risk factors associated with HCC at baseline. Linear regression models were used to assess these associations and analyses were adjusted for age at baseline, sex and health district. Principal components analysis was applied to available indicators of household socio-economic status, education, income, ownership of lands and hygiene and sanitation practices to derive a SES index [37]. Food security was defined using the household food insecurity access scale (HFIAS) [38] and information on IYCF practices (breastfeeding, dietary diversity and food frequency) were used to estimate the adequate dietary diversity (ADD), minimum meal frequency (MMF) and consumption of iron-rich foods as specified by WHO [39,40].

For the third objective, we explored associations between endline HCC and morbidity burden between mid-point (18 weeks after enrollment) and endline corresponding to the previous 3-4 months. This time period was chosen because a previous study reported that a hair sample of $2-3 \mathrm{~cm}$ reflects the average HCC over the previous $2-3$ months, assuming a hair growth rate of approximately $1 \mathrm{~cm} /$ month [17]. These associations were examined using linear regression models adjusted for intervention groups, age at baseline, sex, and health district. Morbidity outcomes assessed were the longitudinal incidence of diarrhea and reported and measured fever. These outcomes were defined as a dichotomous (yes/no) variable based on the occurrence of at least one episode (yes) during the selected time frame. 


\section{Results}

\subsection{Study Population}

From a total of 529 children who provided hair samples at both baseline and endline assessments, HCC was successfully assessed in 512 children $(n=131$ in the PZ group and $n=127$ in the other 3 groups, respectively; Figure 1).

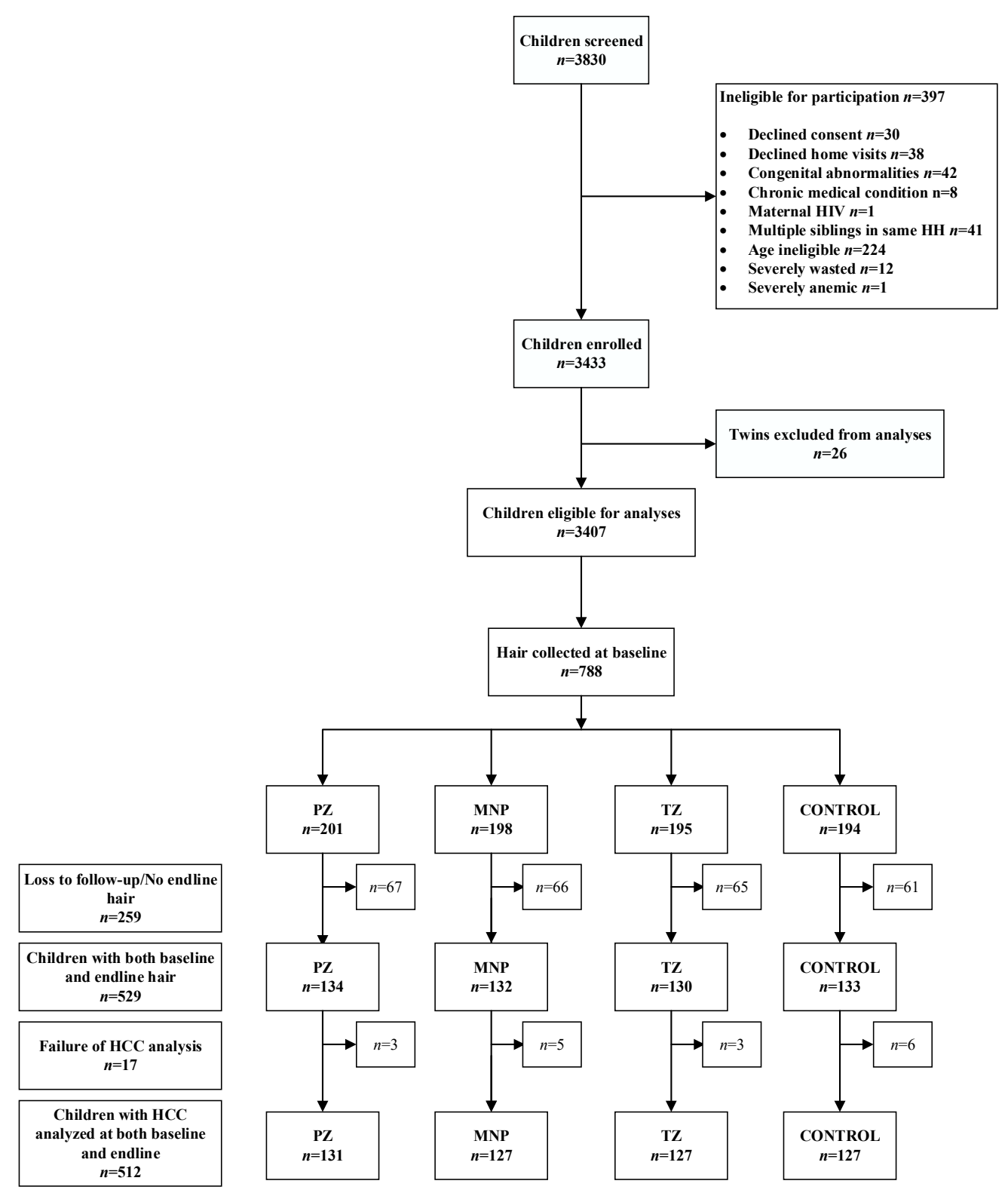

Figure 1. Lao Zinc study flow diagram for hair collection. $\mathrm{MNP}=$ Micronutrient powder; $\mathrm{PZ}=$ preventive zinc; $\mathrm{TZ}=$ Therapeutic zinc.

Mean age at baseline was $15.6 \pm 5.0$ months (Table 1). The prevalence of stunting and underweight was high at $38.2 \%$ and $27.2 \%$, respectively but wasting was less common $(6.3 \%)$. The majority of children were breastfed $(64.4 \%)$ but only about one third of the children $(35.9 \%)$ had adequate dietary diversity at baseline. A total of $16.8 \%$ of the households reported to be severely food insecure. CRP and AGP concentrations were elevated in $11.3 \%$ and $20.0 \%$ of children respectively. Mean HCC at baseline was $28.8 \mathrm{pg} / \mathrm{mg}$ (median (IQR): 21.7 (13.8-35.1)). 
Table 1. Child, maternal and household characteristics of the study participants at baseline by intervention group ${ }^{1}$.

\begin{tabular}{|c|c|c|c|c|c|}
\hline Characteristics & All $(n=512)$ & $\mathrm{PZ}(n=131)$ & MNP $(n=127)$ & $\mathrm{TZ}(n=127)$ & CONTROL $(n=127)$ \\
\hline Age, mo & $15.6 \pm 5.0$ & $15.3 \pm 5.2$ & $15.9 \pm 5.0$ & $15.8 \pm 4.8$ & $15.4 \pm 5.0$ \\
\hline Gender, female & $283(55.3)$ & $79(60.3)$ & $64(50.4)$ & $73(57.5)$ & $67(52.8)$ \\
\hline Breastfeeding & $298(64.4)$ & $72(63.7)$ & $70(62.5)$ & $78(65.6)$ & $78(65.6)$ \\
\hline${ }^{2}$ Adequate dietary diversity & $167(35.9)$ & $39(34.5)$ & $39(34.5)$ & $38(31.7)$ & $51(42.9)$ \\
\hline${ }^{3}$ Minimum meal frequency & $258(55.7)$ & $63(55.8)$ & $60(53.6)$ & $65(54.6)$ & $70(58.8)$ \\
\hline Consumption of iron rich foods & $371(79.8)$ & $83(73.5)$ & $93(82.3)$ & $101(84.2)$ & $94(79.0)$ \\
\hline \multicolumn{6}{|l|}{ Child anthropometric measures } \\
\hline Length, $\mathrm{cm}$ & $73.8 \pm 5.4$ & $73.3 \pm 5.6$ & $74.0 \pm 5.2$ & $73.6 \pm 5.2$ & $74.5 \pm 5.6$ \\
\hline Weight, kg & $8.5 \pm 1.3$ & $8.3 \pm 1.3$ & $8.5 \pm 1.3$ & $8.5 \pm 1.3$ & $8.8 \pm 1.3$ \\
\hline MUAC, $\mathrm{cm}$ & $13.9 \pm 1.0$ & $13.8 \pm 1.0$ & $13.9 \pm 1.0$ & $14.0 \pm 1.0$ & $14.1 \pm 1.0$ \\
\hline LAZ & $-0.71 \pm 1.08$ & $-1.79 \pm 1.10$ & $-1.79 \pm 1.10$ & $-1.86 \pm 1.07$ & $-1.41 \pm 1.07$ \\
\hline WAZ & $-1.42 \pm 0.99$ & $-1.52 \pm 1.00$ & $-1.52 \pm 1.04$ & $-1.51 \pm 0.96$ & $-1.14 \pm 0.93$ \\
\hline WLZ & $-0.74 \pm 0.86$ & $-0.81 \pm 0.89$ & $-0.82 \pm 0.86$ & $-0.76 \pm 0.87$ & $-0.57 \pm 0.82$ \\
\hline Stunting & $195(38.2)$ & $52(40.0)$ & $52(40.9)$ & $54(42.5)$ & $37(29.1)$ \\
\hline Wasting & $32(6.3)$ & $11(8.5)$ & $12(9.5)$ & $7(5.5)$ & $2(1.6)$ \\
\hline Underweight & $139(27.2)$ & $40(30.8)$ & $41(32.3)$ & $38(29.9)$ & $20(15.8)$ \\
\hline Elevated CRP (>5 mg/L) & $55(11.3)$ & $16(12.6)$ & $9(7.44)$ & $14(11.5)$ & $16(13.9)$ \\
\hline Elevated AGP (>1 g/L) & $97(20.0)$ & $27(21.3)$ & $24(19.8)$ & $22(18.0)$ & $24(20.9)$ \\
\hline Hair cortisol concentrations, $\mathrm{pg} / \mathrm{mg}$ & $21.7(13.8-35.1)$ & $27.0(14.7-38.3)$ & $19.4(12.5-29.7)$ & $21.0(13.4-34.4)$ & $21.5(14.0-34.0)$ \\
\hline Maternal education, primary or lower & $267(53.3)$ & $72(56.7)$ & $67(52.8)$ & $64(51.6)$ & $64(52.0)$ \\
\hline Maternal BMI, $\mathrm{kg} / \mathrm{m}^{2}$ & $22.0 \pm 3.3$ & $21.8 \pm 3.1$ & $22.2 \pm 3.2$ & $21.9 \pm 3.4$ & $22.0 \pm 3.5$ \\
\hline \multicolumn{6}{|l|}{ HFIAS } \\
\hline Food secure & $131(25.9)$ & $35(27.3)$ & $35(28.2)$ & $25(19.7)$ & $36(28.6)$ \\
\hline Mildly food insecure & $148(29.3)$ & $35(27.3)$ & $37(29.8)$ & $39(30.7)$ & $37(29.4)$ \\
\hline Moderately food insecure & $141(27.9)$ & $26(20.3)$ & $36(29.0)$ & $42(33.1)$ & $37(29.4)$ \\
\hline Severely food insecure & $85(16.8)$ & $32(25.0)$ & $16(12.9)$ & $21(16.5)$ & $16(12.7)$ \\
\hline
\end{tabular}

${ }^{1}$ Values presented as $\mathrm{n}(\%)$, means \pm SDs or medians (IQRs). AGP: $\alpha_{1}$-acid glycoprotein; BMI: body mass index; CRP: C-reactive protein; HFIAS: household food insecurity access scale [38]; LAZ: length-for-age $z$-score; MNP: micronutrient powder; MUAC: mid-upper arm circumference; PZ: preventive zinc; TZ: therapeutic zinc; WAZ, weight-for-age z-score; WLZ, weight-for-length $z$-score. ${ }^{2}$ Adequate dietary diversity: Proportion of children 6-23 months of age who receive foods from 4 or more food groups. ${ }^{3}$ Minimum meal frequency: Proportion of breastfed and non-breastfed children 6-23 months of age who receive solid, semi-solid, or soft foods the minimum number of times or more. 
Compared to the children participating in the main trial, those included in this analysis were older (15.6 mo vs. 14.0 mo, $p<0.001)$, more likely to be female $(55.3 \%$ vs. $48.4 \%, p=0.004)$, and severely food insecure $(16.8 \%$ vs. $12.4 \%, p<0.001)$. They were less likely to be breastfed $(64.4 \%$ vs. $74.4 \%, p<0.001$ ) but have better reported IYCF practices (adequate dietary diversity: $35.9 \%$ vs. $10.1 \%$, minimum meal frequency, $55.7 \%$ vs. $46.9 \%$, consumption of iron-rich foods: $79.9 \%$ vs. $64.7 \%$; all $p<0.001)$. The prevalence of stunting, wasting and underweight were not significantly different between the 2 cohorts of children (data not shown).

\subsection{Impact of the Study Interventions on HCC}

In both minimally adjusted (adjusted for baseline value of HCC, age, district) and fully adjusted (adjusted for baseline value of HCC, age, district, sex, LAZ, WAZ, wasting, health center and maternal marital status) models, endline HCC did not differ significantly across the four groups ( $p=0.231$ and $p=0.260$, respectively; Table 2). There was no overall effect on change in HCC $(p=0.121)$ in the minimally adjusted model. There was a statistically marginal effect on change in HCC in the fully adjusted model $(p=0.075)$. Specifically, the reduction in HCC was slightly lower in the TZ group than in the PZ group (mean change $(95 \% \mathrm{CI}):-4.6(-7.0 ;-2.3)$ vs. $-9.4(-11.7 ;-7.0) \mathrm{pg} / \mathrm{mg}$, respectively; $p=0.053)$.

Table 2. Effects of daily preventive zinc, micronutrient powder or therapeutic zinc for diarrhea on hair cortisol concentrations (HCC) among Laotian children ${ }^{1}$.

\begin{tabular}{|c|c|c|c|c|c|c|}
\hline & $n$ & $\mathbf{P Z}$ & MNP & $\mathrm{TZ}$ & CONTROL & $P$ \\
\hline \multicolumn{7}{|l|}{${ }^{2} \mathrm{HCC}$ at endline, pg/mg } \\
\hline Minimally adjusted model & 512 & $14.3(12.5 ; 16.4)$ & $13.3(11.6 ; 15.3)$ & $16.1(14.0 ; 18.4)$ & $13.6(11.8 ; 15.6)$ & 0.231 \\
\hline Fully adjusted model & 499 & $13.6(11.8 ; 15.6)$ & $13.1(11.4 ; 15.1)$ & $15.9(13.8 ; 18.3)$ & $13.7(11.9 ; 15.9)$ & 0.260 \\
\hline \multicolumn{7}{|l|}{${ }^{3}$ Change in $\mathrm{HCC}, \mathrm{pg} / \mathrm{mg}$} \\
\hline Minimally adjusted model & 512 & $-8.9(-11.2 ;-6.6)$ & $-7.8(-10.2 ;-5.4)$ & $-5.0(-7.4 ;-2.6)$ & $-7.8(-10.2 ;-5.4)$ & 0.121 \\
\hline Fully adjusted model & 499 & $-9.4(-11.7 ;-7.0)$ & $-7.7(-10.1 ;-5.4)$ & $-4.6(-7.0 ;-2.3)$ & $-7.2(-9.7 ;-4.8)$ & 0.078 \\
\hline
\end{tabular}

\subsection{Risk Factors Associated with HCC at Baseline}

In analyses examining potential risk factors associated with HCC at baseline (Table 3), maternal age, education, marital status and BMI were not associated with baseline HCC. Similarly, SES index and HFIAS were not associated with HCC at baseline. However, baseline child consumption of iron rich foods was negatively associated with HCC at baseline, whereas AGP concentration, elevated AGP, elevated CRP and high sTfR were positively associated with HCC at baseline. In addition, the associations between baseline HCC and breastfeeding, child weight, length, low MUAC and CRP concentration at baseline were marginally significant $(p<0.1)$. 
Table 3. Associations between baseline HCC and potential risk factors among Laotian children ${ }^{1}$.

\begin{tabular}{|c|c|c|}
\hline Variables & Percent Change $^{2}$ (95\% CI) & $p$ \\
\hline \multicolumn{3}{|l|}{ Child } \\
\hline Weight, kg & $-6.7(-13.9 ; 1.3)$ & 0.094 \\
\hline Length, $\mathrm{cm}$ & $-2.4(-5.0 ; 0.3)$ & 0.083 \\
\hline MUAC, $\mathrm{cm}$ & $-6.5(-13.8 ; 1.4)$ & 0.106 \\
\hline LAZ & $-5.6(-12.4 ; 1.8)$ & 0.132 \\
\hline WAZ & $-6.0(-13.2 ; 1.9)$ & 0.130 \\
\hline WLZ & $-3.0(-11.6 ; 6.3)$ & 0.512 \\
\hline Stunting & $-6.7(-20.7 ; 9.9)$ & 0.408 \\
\hline Wasting & $7.0(-22.8 ; 48.3)$ & 0.683 \\
\hline Underweight & $3.3(-13.5 ; 23.5)$ & 0.717 \\
\hline Low MUAC (MUAC $\leq 12.5 \mathrm{~cm})$ & $32.4(-4.8 ; 84.1)$ & 0.095 \\
\hline Breastfeeding & $19.0(-1.5 ; 43.8)$ & 0.071 \\
\hline Iron rich foods & $-23.9(-38.8 ;-5.4)$ & 0.014 \\
\hline Adequate dietary diversity & $-11.4(-25.9 ; 6.0)$ & 0.186 \\
\hline Minimum meal frequency & $-10.1(-24.5 ; 7.0)$ & 0.231 \\
\hline $\mathrm{CRP}, \mathrm{mg} / \mathrm{L}$ & $5.4(-0.2 ; 11.4)$ & 0.058 \\
\hline Elevated CRP $(\mathrm{CRP}>5 \mathrm{mg} / \mathrm{L})$ & $19.6(-7.5 ; 54.7)$ & 0.172 \\
\hline $\mathrm{AGP}, \mathrm{g} / \mathrm{L}$ & $30.3(12.4 ; 51.1)$ & $<0.001$ \\
\hline Elevated AGP (AGP > $1 \mathrm{~g} / \mathrm{L})$ & $39.2(13.2 ; 70.6)$ & 0.002 \\
\hline $\mathrm{RBP}, \mathrm{mg} / \mathrm{dL}$ & $-14.3(-36.5 ; 15.8)$ & 0.316 \\
\hline Ferritin, $\mu \mathrm{g} / \mathrm{L}$ & $6.9(-4.0 ; 19.1)$ & 0.221 \\
\hline Low ferritin $(\mathrm{pF}<12 \mu \mathrm{g} / \mathrm{L})$ & $-4.7(-24.5 ; 20.3)$ & 0.687 \\
\hline $\mathrm{sTfR}, \mathrm{mg} / \mathrm{L}$ & $6.9(-11.7 ; 29.4)$ & 0.495 \\
\hline High sTfR $(\mathrm{sTfR}>8.3 \mathrm{mg} / \mathrm{L})$ & $23.5(4.1 ; 46.7)$ & 0.016 \\
\hline \multicolumn{3}{|l|}{ Maternal } \\
\hline Age & $-1.0(-2.3 ; 0.3)$ & 0.135 \\
\hline Education & $-4.3(-18.5 ; 12.3)$ & 0.589 \\
\hline Marital status (couple) & $25.0(-23.0 ; 103.0)$ & 0.367 \\
\hline BMI & $1.8(-0.8 ; 4.4)$ & 0.172 \\
\hline \multicolumn{3}{|l|}{ Household } \\
\hline SES index & $-2.9(-6.9 ; 1.3)$ & 0.175 \\
\hline \multicolumn{3}{|l|}{ HFIAS } \\
\hline Food secure & Ref & \\
\hline Mildly food insecure & $-5.6(-24.0 ; 17.3)$ & 0.604 \\
\hline Moderately food insecure & $0.9(-19.4 ; 26.3)$ & 0.939 \\
\hline Severely food insecure & $-7.0(-28.1 ; 20.2)$ & 0.578 \\
\hline
\end{tabular}

\footnotetext{
${ }^{1}$ Estimates units are percentage, $n=512$ for child characteristics; $n=499$ for maternal and household characteristics. Linear regression models adjusted for age at baseline, sex and district were used to examine potential risk factors associated with HCC at baseline. AGP: $\alpha_{1}$-acid glycoprotein; BMI: body mass index; CRP: C-reactive protein; HFIAS: household food insecurity access scale [38]; LAZ, length-for-age $z$-score; MUAC: mid-upper arm circumference; RBP: retinol binding protein; SES: socio-economic status; sTfR: soluble transferrin receptor; WAZ, weight-for-age $z$-score; WLZ, weight-for-length $z$-score. ${ }^{2}$ Hair cortisol concentration was log transformed for analysis and the estimates reported here are back transformed percent change. The exponential function in excel was used for the back-transformations. These are understood to be the percent change associated with a 1 unit increase in the variable indicated: a negative estimate means that the presence or an increase of 1 unit of a risk factor is associated with the estimate percent decrease of HCC and a positive estimate means that the presence or an increase of 1 unit of a risk factor is associated with the estimate percent increase of HCC.
}

\subsection{Association Between Endline HCC and Diarrhea and Fever in the Previous 3 Months}

Caregivers reported at least one episode of diarrhea in $46.5 \%$ of children, while fever was reported or measured at least once among $74.6 \%$ and $11.7 \%$ of children, respectively. Neither the presence of reported diarrhea $(p=0.666)$, nor reported $(p=0.520)$ or measured $(p=0.560)$ fever in the previous 3-4 months were associated with HCC at endline (Table 4). 
Table 4. Associations between endline HCC and morbidity in the previous 3 months ${ }^{1}$.

\begin{tabular}{cccc}
\hline Variables & $\boldsymbol{n ( \% )}$ & Percent Change $^{\mathbf{2}} \mathbf{( 9 5 \% \mathbf { C I } )}$ & $\boldsymbol{p}$ \\
\hline Reported at least 1 episode of diarrhea & $238(46.5)$ & $3.1(-10.4 ; 18.7)$ & 0.666 \\
Reported at least 1 episode of fever & $382(74.6)$ & $5.4(-10.3 ; 23.9)$ & 0.520 \\
Measured at least 1 episode of fever & $60(11.7)$ & $6.7(-14.2 ; 32.6)$ & 0.560 \\
\hline
\end{tabular}

${ }^{1}$ Estimates units are percentage. Linear regression models adjusted for intervention group, age at endline, sex and district were used to explore associations between endline HCC and morbidity burden in the previous 3-4 months.

${ }^{2}$ Hair cortisol concentration was log transformed for analysis and the estimates reported here are back transformed percent change. The exponential function in excel was used for the back-transformations.

\section{Discussion}

Growing evidence indicates that HCC may be an objective biomarker of chronic stress, and given that zinc supplementation has been reported to reduce the morbidity burden, we hypothesized that zinc supplementation may reduce chronic stress by affecting the immune function and the morbidity burden. Thus, we examined the impact of different strategies for delivering supplementary zinc on HCC among young Laotian children. In our study population of 512 young children aged 6-23 months at enrolment, we found no significant impact of the different zinc supplementation strategies on HCC. However, there was a marginal difference in change in HCC between the preventive zinc and therapeutic zinc groups after statistical adjustment. This difference was too small to be considered of health significance.

To explore whether HCC may be a useful indicator of nutritional and health status during early childhood, we examined the association between HCC and potential risk factors and found that children's CRP, AGP concentrations, high sTfR levels and lack of consumption of iron rich foods were risk factors for elevated HCC at baseline. We are uncertain why or how breastfeeding would be inversely associated with HCC and assume that this may be a chance finding. In contrast, the child's stunting and wasting status were not associated with baseline HCC. We also found no associations between maternal characteristics (age, education, BMI), household SES status and baseline HCC. Furthermore, we evaluated the association between HCC and longitudinal morbidity and found that diarrheal and febrile morbidity in the previous 3-4 months did not translate into an increased HCC at endline.

It is unclear whether our intervention had no impact on HCC because (1) the tested interventions had no impact on chronic stress, or (2) the study population was not under chronic stress or (3) HCC is not a sensitive marker of chronic stress in this population. We will address each of these points below.

As previously reported, the present study found no overall impact of PZ, MNP and TZ on growth and morbidity outcomes, such as diarrhea, fever and respiratory distress [41,42], although $\mathrm{TZ}$ reduced the incidence and duration of diarrhea episodes in older children $(>18 \mathrm{mo})$, but not in younger ones. This beneficial impact on diarrhea outcomes did not result in lower HCC in the TZ group, nor did age have a modifying effect on HCC. Although MNP had no overall impact on growth and morbidity, we found that the provision of MNP was associated with a small adverse effect on linear growth among non-anemic children and on diarrhea among children with inherited hemoglobin disorders [43]. Neither the beneficial nor the adverse effects observed in the Lao Zinc Study were reflected in the HCC, which was possibly due to the small magnitude of the effect or the limited sample size of children with HCC results in the respective subgroups. Another reason for the lack of impact of our interventions could be the relatively short duration of the intervention. We followed our study participants for $\sim 36$ weeks. Although this duration is consistent with previous studies of preventive zinc supplementation that found an impact on growth and morbidity outcomes [26,44,45], the duration may have been inadequate to affect an indicator of chronic stress such as HCC. To the best of our knowledge, this study is the first intervention study to assess the impact of different strategies for delivering supplementary zinc or other micronutrients on HCC, making any comparison with 
the existing literature difficult. More evidence from supplementation trials is needed to understand whether zinc and MNP supplementation has an impact on chronic stress as reflected in HCC.

Another reason for the apparent lack of impact of our interventions on HCC may be that our study population was not under chronic stress, and thus HCC would not respond to supplementation. There are currently no cut-offs for HCC to define chronic stress. Mean baseline HCC in our study population was $28.8 \mathrm{pg} / \mathrm{mg}$ which is similar to mean HCC $(27.33 \mathrm{pg} / \mathrm{mg})$ in 12 month old infants in Boston [46] but higher than the mean HCC of the majority of the previous studies [20], although there is a wide range in HCC reported in the literature, ranging from $5.0 \mathrm{pg} / \mathrm{mg}$ in $4-5$ years old Dutch children [47] to $40.9 \mathrm{pg} / \mathrm{mg}$ in 1-9 years old German children [48] and $535.3 \mathrm{pg} / \mathrm{mg}$ in 3-18 years old subjects from Central African Republic and Ethiopia [49]. Unfortunately, there are no published studies on HCC in 0-2 years old infants in low- and lower-middle-income countries. There was a high prevalence of stunting (38.2\%), underweight $(27.2 \%)$, zinc deficiency $(75.4 \%)$ and iron deficiency $(26.1 \%)$ in the study population, suggesting that many of these children may experience other types of chronic stress.

Even though studies have used direct validation and different strategies to indirectly validate hair cortisol as a biomarker of chronic stress [50], only weak correlations have been reported between psychological tests (perceived stress for example) and HCC [51,52], raising some concerns regarding its utility and applicability as a sensitive marker of childhood chronic stress. The risk factors associated with HCC in children have been previously examined [20] and mixed findings have been reported in regards to household socio-economic status [30,53,54], ethnicity [30,55], maternal education [30,56], child age $[47,48]$ and gender $[48,57]$. It is worth mentioning that studies which reported socio-economic status, maternal education and child age to be risk factors of HCC $[30,53]$ included older children than those in the present study. Child age was not an effect modifier in our study. However, the age range in the present study was limited compared to some of the prior investigations in other populations mentioned above. Although the present study was implemented in rural communities of central Laos, children included in our study were young (6-23 mo) and may have either not had enough cumulative exposure to the effects of low socioeconomic status, or may use effective buffering mechanisms such that these associations do not emerge.

The association between HCC and child nutritional and health status has not previously been examined. We found that HCC was not significantly associated with child anthropometric measurements such as length, weight, MUAC, LAZ, WAZ, WLZ, stunting, wasting and underweight. In addition, no previous study has examined the associations between HCC and morbidity and we found no association between HCC and morbidity in the 3-4 months prior to endline hair collection. Moreover, HCC was neither associated with factors such as food security, adequate dietary diversity and minimum meal frequency. This lack of association between HCC and child nutritional and health status questions and challenges the usefulness of HCC as a sensitive marker of child nutritional and health status.

Previous studies found a high variability in HCC among different age groups [20]. Hair sample collection method is unlikely to be a source of variability between our findings and other studies. As in other studies [58,59], we cut hair in accordance with the guidelines published by the Society of Hair Testing [60] from above the nape of the neck as close to the scalp as possible. Hair from this region has been reported to be the standard for hair analysis and to have higher cortisol levels compared with hair from other regions [61]. However, cortisol in hair is usually quantified using enzyme linked immunosorbent assay (ELISA) and high performance liquid chromatography-mass spectrometry (HPLC/MS) [62] and given the multitude of commercially available cortisol kits, the HCC detection method is more likely to be a source of the variability found. Other potential biases of the study could include the color of hair, but considering that the study was implemented in Laos, there was very little diversity in hair color. Data on hair care characteristics in terms of washing frequency, and use of hair products or type of hair products were not collected mainly because of the age-range of our study participants (6-32 months old). Previous studies that collected data on hair care characteristics 
were done in adults [63] or in older children (4-14 years old) [47] and findings from these studies have reported that HCC were not affected by hair color, hair washing frequency or use of hair products.

A notable strength of this study is its randomized placebo-controlled trial design, the high participation rate and the rigorous data collection, which included both regular training of data collectors and frequent supervision. The vast amount of collected data allowed the investigation of potential risk factors associated with HCC. This study also has some limitations. Adherence to the supplementation was based on weekly caregiver reports, which has been shown to be unreliable [64]. However, plasma zinc concentrations increased in the PZ and the MNP groups and ferritin concentrations increased in MNP group as expected and thus suggest that adherence was adequate [41]. In addition, hair samples were collected from a convenience sample for logistical reasons. However, hair collection was implemented among all four intervention groups simultaneously until the respective target sample size was achieved [31].

\section{Conclusions}

In this population of young Laotian children, supplementation with zinc alone or combined with other micronutrients as an MNP had no impact on HCC. The marginal difference in change in HCC between preventive and therapeutic zinc groups was too small to be considered of health significance. Additional research is needed to examine the usefulness of HCC as an indicator of child health status.

Author Contributions: Conceptualization, G.-M.H., R.M.B., K.R.W., S.K. and S.Y.H.; Data curation, G.-M.H., M.A.B. and C.D.A.; Formal analysis, G.-M.H. and C.D.A.; Funding acquisition, S.K. and S.Y.H.; Investigation, G.-M.H., R.M.B. and M.A.B.; Methodology, G.-M.H., R.M.B., M.A.B., C.D.A., K.R.W. and S.Y.H.; Project administration, G.-M.H., M.A.B., K.R.W., K.R., B.B., S.K. and S.Y.H.; Resources, R.M.B., S.K. and S.Y.H.; Supervision, G.-M.H., M.A.B., K.R.W., S.K. and S.Y.H.; Validation, R.M.B.; Visualization, G.-M.H. and S.Y.H.; Writing-original draft, G.-M.H.; Writing—review \& editing, G.-M.H., R.M.B., M.A.B., C.D.A., K.R.W., K.R., B.B., S.K. and S.Y.H.

Funding: Funding for this research was provided by the Bill \& Melinda Gates Foundation, Nutrition International (formerly known as the Micronutrient Initiative) and the Mathile Institute for the Advancement of Human Nutrition.

Acknowledgments: We thank the entire Lao Zinc Study team, Dalaphone Sitthideth, Khanpaseuth Sengnam and Bigphone Chanhthavong (Lao Tropical and Public Health Institute, Vientiane Lao People's Democratic Republic) for coordinating the data collection and Kendall Abady (Department of Anthropology, University of Colorado, Boulder, CO, USA) for helping with the hair cortisol analyses. In addition, we sincerely thank all of the participating children and their parents, the local communities and health districts of the Khammouane Province, Lao PDR.

Conflicts of Interest: The spouse of S.Y.H. works for the Bill \& Melinda Gates Foundation.

\section{References}

1. Timmermans, M.; van Lier, P.A.; Koot, H.M. The role of stressful events in the development of behavioural and emotional problems from early childhood to late adolescence. Psychol. Med. 2010, 40, 1659-1668. [CrossRef] [PubMed]

2. Shonkoff, J.P.; Boyce, W.T.; McEwen, B.S. Neuroscience, molecular biology, and the childhood roots of health disparities: Building a new framework for health promotion and disease prevention. JAMA 2009, 301, 2252-2259. [CrossRef] [PubMed]

3. Danese, A.; McEwen, B.S. Adverse childhood experiences, allostasis, allostatic load, and age-related disease. Physiol. Behav. 2012, 106, 29-39. [CrossRef] [PubMed]

4. Gunnar, M.; Quevedo, K. The neurobiology of stress and development. Annu. Rev. Psychol. 2007, 58, $145-173$. [CrossRef] [PubMed]

5. Doom, J.R.; Gunnar, M.R. Stress physiology and developmental psychopathology: Past, present, and future. Dev. Psychopathol. 2013, 25, 1359-1373. [CrossRef] [PubMed]

6. Vanaelst, B.; De Vriendt, T.; Huybrechts, I.; Rinaldi, S.; De Henauw, S. Epidemiological approaches to measure childhood stress. Paediatr. Perinat. Epidemiol. 2012, 26, 280-297. [CrossRef] [PubMed] 
7. Ouellet-Morin, I.; Laurin, M.; Robitaille, M.P.; Brendgen, M.; Lupien, S.J.; Boivin, M.; Vitaro, F. Validation of an adapted procedure to collect hair for cortisol determination in adolescents. Psychoneuroendocrinology 2016, 70, 58-62. [CrossRef] [PubMed]

8. Russell, E.; Koren, G.; Rieder, M.; Van Uum, S. Hair cortisol as a biological marker of chronic stress: Current status, future directions and unanswered questions. Psychoneuroendocrinology 2012, 37, 589-601. [CrossRef]

9. Hanrahan, K.; McCarthy, A.M.; Kleiber, C.; Lutgendorf, S.; Tsalikian, E. Strategies for salivary cortisol collection and analysis in research with children. Appl. Nurs. Res. 2006, 19, 95-101. [CrossRef]

10. Kidd, S.; Midgley, P.; Lone, N.; Wallace, A.M.; Nicol, M.; Smith, J.; McIntosh, N. A re-investigation of saliva collection procedures that highlights the risk of potential positive interference in cortisol immunoassay. Steroids 2009, 74, 666-668. [CrossRef]

11. Remer, T.; Maser-Gluth, C.; Wudy, S.A. Glucocorticoid measurements in health and disease-metabolic implications and the potential of 24-h urine analyses. Mini Rev. Med. Chem. 2008, 8, 153-170. [CrossRef] [PubMed]

12. D'Anna-Hernandez, K.L.; Ross, R.G.; Natvig, C.L.; Laudenslager, M.L. Hair cortisol levels as a retrospective marker of hypothalamic-pituitary axis activity throughout pregnancy: Comparison to salivary cortisol. Physiol. Behav. 2011, 104, 348-353. [CrossRef] [PubMed]

13. Kirschbaum, C.; Tietze, A.; Skoluda, N.; Dettenborn, L. Hair as a retrospective calendar of cortisol productionincreased cortisol incorporation into hair in the third trimester of pregnancy. Psychoneuroendocrinology 2009, 34, 32-37. [CrossRef]

14. Stalder, T.; Steudte, S.; Miller, R.; Skoluda, N.; Dettenborn, L.; Kirschbaum, C. Intraindividual stability of hair cortisol concentrations. Psychoneuroendocrinology 2012, 37, 602-610. [CrossRef]

15. Short, S.J.; Stalder, T.; Marceau, K.; Entringer, S.; Moog, N.K.; Shirtcliff, E.A.; Wadhwa, P.D.; Buss, C. Correspondence between hair cortisol concentrations and 30-day integrated daily salivary and weekly urinary cortisol measures. Psychoneuroendocrinology 2016, 71, 12-18. [CrossRef]

16. Grass, J.; Kirschbaum, C.; Miller, R.; Gao, W.; Steudte-Schmiedgen, S.; Stalder, T. Sweat-inducing physiological challenges do not result in acute changes in hair cortisol concentrations. Psychoneuroendocrinology 2015, 53, 108-116. [CrossRef]

17. Sauve, B.; Koren, G.; Walsh, G.; Tokmakejian, S.; Van Uum, S.H. Measurement of cortisol in human hair as a biomarker of systemic exposure. Clin. Investig. Med. 2007, 30, E183-E191. [CrossRef]

18. Stalder, T.; Kirschbaum, C. Analysis of cortisol in hair-state of the art and future directions. Brain Behav. Immun. 2012, 26, 1019-1029. [CrossRef]

19. Vanaelst, B.; Huybrechts, I.; Bammann, K.; Michels, N.; de Vriendt, T.; Vyncke, K.; Sioen, I.; Iacoviello, L.; Gunther, K.; Molnar, D.; et al. Intercorrelations between serum, salivary, and hair cortisol and child-reported estimates of stress in elementary school girls. Psychophysiology 2012, 49, 1072-1081.

20. Bates, R.; Salsberry, P.; Ford, J. Measuring stress in young children using hair cortisol: The state of the science. Biol. Res. Nurs. 2017, 19, 499-510. [CrossRef]

21. King, J.C.R. Zinc. In Modern Nutrition in Health and Disease, 11th ed.; Shils, M.E., Shike, M., Ross, A.C., Caballero, B., Cousins, R.J., Eds.; Lippincott Williams \& Wilkins: Philadelphia, PA, USA, 2014; pp. 189-205.

22. Brown, K.H.; Peerson, J.M.; Baker, S.K.; Hess, S.Y. Preventive zinc supplementation among infants, preschoolers, and older prepubertal children. Food Nutr. Bull. 2009, 30, S12-S40. [CrossRef] [PubMed]

23. Mayo-Wilson, E.; Junior, J.A.; Imdad, A.; Dean, S.; Chan, X.H.; Chan, E.S.; Jaswal, A.; Bhutta, Z.A. Zinc supplementation for preventing mortality, morbidity, and growth failure in children aged 6 months to 12 years of age. Cochrane Database Syst. Rev. 2014, CD009384. [CrossRef]

24. Aggarwal, R.; Sentz, J.; Miller, M.A. Role of zinc administration in prevention of childhood diarrhea and respiratory illnesses: A meta-analysis. Pediatrics 2007, 119, 1120-1130. [CrossRef]

25. Yakoob, M.Y.; Theodoratou, E.; Jabeen, A.; Imdad, A.; Eisele, T.P.; Ferguson, J.; Jhass, A.; Rudan, I.; Campbell, H.; Black, R.E.; et al. Preventive zinc supplementation in developing countries: Impact on mortality and morbidity due to diarrhea, pneumonia and malaria. BMC Public Health 2011, 11 (Suppl. 3), S23. [CrossRef] [PubMed]

26. De-Regil, L.M.; Suchdev, P.S.; Vist, G.E.; Walleser, S.; Pena-Rosas, J.P. Home fortification of foods with multiple micronutrient powders for health and nutrition in children under two years of age. Cochrane Database Syst. Rev. 2011, CD008959. [CrossRef] [PubMed] 
27. Salam, R.A.; MacPhail, C.; Das, J.K.; Bhutta, Z.A. Effectiveness of micronutrient powders (mnp) in women and children. BMC Public Health 2013, 13 (Suppl. 3), S22.

28. World Health Organization. Clinical Management of Acute Diarrhoea. Who/Unicef Joint Statement. Report No.: Who/fch/cah/04.7; WHO: Geneva, Switzerland, 2004.

29. Lazzerini, M.; Ronfani, L. Oral zinc for treating diarrhoea in children. Cochrane Database Syst. Rev. 2013, CD005436. [CrossRef]

30. Vaghri, Z.; Guhn, M.; Weinberg, J.; Grunau, R.E.; Yu, W.; Hertzman, C. Hair cortisol reflects socio-economic factors and hair zinc in preschoolers. Psychoneuroendocrinology 2013, 38, 331-340. [CrossRef]

31. Wessells, K.R.; Brown, K.H.; Kounnavong, S.; Barffour, M.A.; Hinnouho, G.; Sayasone, S.; Stephensen, C.B.; Ratsavong, R.; Larson, C.P.; Arnold, C.D.; et al. Comparison of two forms of daily preventive zinc supplementation versus therapeutic zinc supplementation for diarrhea on young children's physical growth and risk of infection: Study design and rationale for a randomized controlled trial. BMC Nutr. 2018, 4, 39. [CrossRef]

32. WHO Multicentre Growth Reference Study Group. Who Child Growth Standards: Length/height-For-Age, Weight-For-Age, Weight-For-Length, Weight-For-Height and Body Mass Index-For-Age: Methods and Development; World Health Organization: Geneva, Switzerland, 2006.

33. Adu-Afarwuah, S.; Lartey, A.; Brown, K.H.; Zlotkin, S.; Briend, A.; Dewey, K.G. Home fortification of complementary foods with micronutrient supplements is well accepted and has positive effects on infant iron status in ghana. Am. J. Clin. Nutr. 2008, 87, 929-938. [CrossRef]

34. Cogill, B. Anthropometric Indicators Measurement Guide; Food and Nutrition Technical Assistance: Washington, DC, USA, 2003.

35. Erhardt, J.G.; Estes, J.E.; Pfeiffer, C.M.; Biesalski, H.K.; Craft, N.E. Combined measurement of ferritin, soluble transferrin receptor, retinol binding protein, and c-reactive protein by an inexpensive, sensitive, and simple sandwich enzyme-linked immunosorbent assay technique. J. Nutr. 2004, 134, 3127-3132. [CrossRef] [PubMed]

36. Hess, S.; Barffour, M.; Hinnouho, G. Lao Zinc Study. Open Science Framework. Available online: https: / / osf.io/5bq9c (accessed on 6 April 2018).

37. Vyas, S.; Kumaranayake, L. Constructing socio-economic status indices: How to use principal components analysis. Health Policy Plan. 2006, 21, 459-468. [CrossRef] [PubMed]

38. Coates, J. Anne Swindale and Paula Bilinsky. Household Food Insecurity Access Scale (Hfias) for Measurement of Household food Access: Indicator Guide (V. 3); FHI 360/FANTA: Washington, DC, USA, 2007.

39. World Health Organization. Indicators for Assessing Infant and Young Child Feeding Practices. Part. I: Definition; World Health Organization: Geneva, Switzerland, 2008.

40. World Health Organization. Indicators for Assessing Infant and Young Child Feeding Practices. Part. II: Measurement; World Health Organization: Geneva, Switzerland, 2010.

41. Barffour, M.A.; Hinnouho, G.M.; Kounnavong, S.; Wessells, K.R.; Ratsavong, K.; Bounheuang, B.; Chanhthavong, B.; Sitthideth, D.; Sengnam, K.; Arnold, C.D.; et al. Effects of daily preventive zinc supplementation, daily supplementation with a high-zinc, low-iron containing multiple micronutrient powder or therapeutic zinc supplementation for diarrhea, on physical growth, anemia and zinc and iron status in rural Laotian children: A randomized controlled trial. J. Pediatr. 2018. [CrossRef]

42. Barffour, M.A.; Hinnouho, G.M.; Kounnavong, S.; Wessells, K.R.; Ratsavong, K.; Bounheuang, B.; Chanhthavong, B.; Sitthideth, D.; Khanpaseuth, S.; Arnold, C.D.; et al. Effects of two forms of daily preventive zinc and therapeutic zinc supplementation for diarrhea on diarrhea and acute respiratory tract infections in laotian children. Curr. Dev. Nutr. 2018, in press.

43. Hess, S.Y.; Wessells, K.R.; Hinnouho, G.M.; Barffour, M.A.; Sanchaisuriya, K.; Arnold, C.D.; Ratsavong, K.; Brown, K.H.; Larson, C.P.; Fucharoen, S.; et al. Associations of genetic hemoglobin disorders and iron status with linear growth and morbidity among young lao children receiving micronutrient powders. Curr. Dev. Nutr. 2018, in press.

44. Ramakrishnan, U.; Nguyen, P.; Martorell, R. Effects of micronutrients on growth of children under $5 \mathrm{y}$ of age: Meta-analyses of single and multiple nutrient interventions. Am. J. Clin. Nutr. 2009, 89, 191-203. [CrossRef] [PubMed]

45. Brown, K.H.; Peerson, J.M.; Rivera, J.; Allen, L.H. Effect of supplemental zinc on the growth and serum zinc concentrations of prepubertal children: A meta-analysis of randomized controlled trials. Am. J. Clin. Nutr. 2002, 75, 1062-1071. [CrossRef] [PubMed] 
46. Flom, M.; St John, A.M.; Meyer, J.S.; Tarullo, A.R. Infant hair cortisol: Associations with salivary cortisol and environmental context. Dev. Psychobiol. 2017, 59, 26-38. [CrossRef]

47. Noppe, G.; Van Rossum, E.F.; Koper, J.W.; Manenschijn, L.; Bruining, G.J.; de Rijke, Y.B.; van den Akker, E.L. Validation and reference ranges of hair cortisol measurement in healthy children. Horm. Res. Paediatr. 2014, 82, 97-102. [CrossRef]

48. Dettenborn, L.; Tietze, A.; Kirschbaum, C.; Stalder, T. The assessment of cortisol in human hair: Associations with sociodemographic variables and potential confounders. Stress 2012, 15, 578-588. [CrossRef]

49. Helfrecht, C.; Hagen, E.H.; DeAvila, D.; Bernstein, R.M.; Dira, S.J.; Meehan, C.L. Dheas patterning across childhood in three sub-saharan populations: Associations with age, sex, ethnicity, and cortisol. Am. J. Hum. Biol. 2018, 30, e23090. [CrossRef] [PubMed]

50. Gerber, M.; Brand, S.; Lindwall, M.; Elliot, C.; Kalak, N.; Herrmann, C.; Puhse, U.; Jonsdottir, I.H. Concerns regarding hair cortisol as a biomarker of chronic stress in exercise and sport science. J. Sports Sci. Med. 2012, 11, 571-581. [PubMed]

51. Dowlati, Y.; Herrmann, N.; Swardfager, W.; Thomson, S.; Oh, P.I.; Van Uum, S.; Koren, G.; Lanctot, K.L. Relationship between hair cortisol concentrations and depressive symptoms in patients with coronary artery disease. Neuropsychiatr. Dis. Treat. 2010, 6, 393-400. [PubMed]

52. Skoluda, N.; Dettenborn, L.; Stalder, T.; Kirschbaum, C. Elevated hair cortisol concentrations in endurance athletes. Psychoneuroendocrinology 2012, 37, 611-617. [CrossRef] [PubMed]

53. Vliegenthart, J.; Noppe, G.; van Rossum, E.F.; Koper, J.W.; Raat, H.; van den Akker, E.L. Socioeconomic status in children is associated with hair cortisol levels as a biological measure of chronic stress. Psychoneuroendocrinology 2016, 65, 9-14. [CrossRef] [PubMed]

54. Rippe, R.C.; Noppe, G.; Windhorst, D.A.; Tiemeier, H.; van Rossum, E.F.; Jaddoe, V.W.; Verhulst, F.C.; Bakermans-Kranenburg, M.J.; van, I.M.H.; van den Akker, E.L. Splitting hair for cortisol? Associations of socio-economic status, ethnicity, hair color, gender and other child characteristics with hair cortisol and cortisone. Psychoneuroendocrinology 2016, 66, 56-64. [CrossRef]

55. Palmer, F.B.; Anand, K.J.; Graff, J.C.; Murphy, L.E.; Qu, Y.; Volgyi, E.; Rovnaghi, C.R.; Moore, A.; Tran, Q.T.; Tylavsky, F.A. Early adversity, socioemotional development, and stress in urban 1-year-old children. J. Pediatr. 2013, 163, 1733-1739. [CrossRef] [PubMed]

56. Karlen, J.; Frostell, A.; Theodorsson, E.; Faresjo, T.; Ludvigsson, J. Maternal influence on child hpa axis: A prospective study of cortisol levels in hair. Pediatrics 2013, 132, e1333-e1340. [CrossRef]

57. Karlen, J.; Ludvigsson, J.; Hedmark, M.; Faresjo, A.; Theodorsson, E.; Faresjo, T. Early psychosocial exposures, hair cortisol levels, and disease risk. Pediatrics 2015, 135, e1450-e1457. [CrossRef]

58. Larsen, S.C.; Fahrenkrug, J.; Olsen, N.J.; Heitmann, B.L. Association between hair cortisol concentration and adiposity measures among children and parents from the "healthy start" study. PLoS ONE 2016, 11, e0163639. [CrossRef]

59. Wester, V.L.; van Rossum, E.F. Clinical applications of cortisol measurements in hair. Eur. J. Endocrinol. 2015, 173, M1-M10. [CrossRef] [PubMed]

60. Cooper, G.A.; Kronstrand, R.; Kintz, P. Society of hair testing guidelines for drug testing in hair. Forensic Sci. Int. 2012, 218, 20-24. [CrossRef] [PubMed]

61. Li, J.; Xie, Q.; Gao, W.; Xu, Y.; Wang, S.; Deng, H.; Lu, Z. Time course of cortisol loss in hair segments under immersion in hot water. Clin. Chim. Acta 2012, 413, 434-440. [CrossRef] [PubMed]

62. Gow, R.; Thomson, S.; Rieder, M.; Van Uum, S.; Koren, G. An assessment of cortisol analysis in hair and its clinical applications. Forensic Sci. Int. 2010, 196, 32-37. [CrossRef] [PubMed]

63. Manenschijn, L.; Koper, J.W.; Lamberts, S.W.; van Rossum, E.F. Evaluation of a method to measure long term cortisol levels. Steroids 2011, 76, 1032-1036. [CrossRef] [PubMed]

64. Abbeddou, S.; Hess, S.Y.; Yakes Jimenez, E.; Some, J.W.; Vosti, S.A.; Guissou, R.M.; Ouedraogo, J.B.; Brown, K.H. Comparison of methods to assess adherence to small-quantity lipid-based nutrient supplements (sq-lns) and dispersible tablets among young burkinabe children participating in a community-based intervention trial. Matern. Child. Nutr 2015, 11 (Suppl. 4), 90-104. [CrossRef]

(C) 2018 by the authors. Licensee MDPI, Basel, Switzerland. This article is an open access article distributed under the terms and conditions of the Creative Commons Attribution (CC BY) license (http:/ / creativecommons.org/licenses/by/4.0/). 